\title{
A Case Study of Early Acquisition of Chinese Modals
}

\author{
Chen Shuzhen \\ Foreign Languages School \\ Linyi University \\ Linyi, China
}

\author{
Ma Yuqian \\ Foreign Languages School \\ Linyi University \\ Linyi, China \\ 15192893626@163.com
}

\begin{abstract}
The present study investigates the emergence and early development of Chinese modals of a single child from $1 ; 8$ to $2 ; 7$ from the lexical, semantic, syntactic and pragmatic perspectives. The results show that: 1) Chinese modals emerge gradually between $1 ; 8-2 ; 5$, and modal forms that are acquired early tend to occur more frequently; 2) compared to dynamic and deontic modals, epistemic modals are later acquired and the use frequency is low; 3) the syntactic structures of modal utterances present a gradual trend from simple to complex; 4) modal utterances indicate the correspondence between semantic interpretation and syntactic distribution.
\end{abstract}

\section{Keywords-Chinese modals; early acquisition; case study}

\section{INTRODUCTION}

Modality is the subjective attitude of expressing the truth of a sentence or the realistic status of an event. Chinese modal meanings can be expressed in several ways, such as main verbs, adverbs, intonation, inflection, auxiliary verbs, particles, adjectives and nouns. Among these ways, modal verbs and adverbs are featured for large quantities, flexible usage and high frequency. For children, they are difficult to learn in the lexical, syntactic, semantic and pragmatic aspects. The present study investigates the emergence and development of Chinese modals of a single child from $1 ; 8$ to $2 ; 7$ with an attempt to explore the early modal acquisition in Mandarin Chinese.

\section{RESEARCH REVIEW}

Modal acquisition is a major topic in the field of children's language acquisition research, and modal typology and grammaticalization are the focus of the study. After the 1960s, children's language acquisition gradually developed into a comprehensive interdisciplinary research field. Foreign psychologists and linguists began to carry out research adopting the methodology of empiricism. They explored the acquisition process of modality from the perspectives of the acquisition sequence of modal expressions, syntactic characteristics of modal sentences, and the correspondence between semantic interpretation and syntactic distribution [2, $4,6,7]$.

The study of children's language acquisition in China started late, and the existing understanding of the Chinese children's modality system is mostly derived from the study of the acquisition of verbs and notional words. In the $2000 \mathrm{~s}$,

This paper is funded by the Shandong Provincial Social Science Planning Research Project. Project No.: 15CWXJ21. scholars began to use natural corpus for case analysis. Studies show that: children generally begin to learn modal words from $1 ; 6-1 ; 10$ (the age of 1 year and 6 months, the age of 1 year and 10 months); epistemic modals emerge later than dynamic and deontic modals, and they occur less frequently; the syntactic structures of modal utterances develop from simple to complex gradually $[1,3,5,9,10]$.

Although great advances have been made in modality and its acquisition, much attention is paid to the acquisition of modal verbs. Besides, lack of the large scale corpus causes the reduction of the effectiveness of the research result. It is hoped that by collecting the spontaneous corpus of a Chinese child, the overall investigation of the early modal acquisition will provide more empirical evidence for modal typology and grammaticalization.

\section{Corpus COLLECTION AND COLLATION}

\section{A. Object of Study}

In this paper, a boy as the object of study, named Wang Jinhan (WJH) with the nickname of "Xiangxiang", was born in Linyi City, Shandong Province. Participants in the recordings include the mother, father, grandparents, brother, aunts, uncles, etc. Their communications with WJH are in Mandarin at home.

\section{B. Corpus Collection}

The videos are recorded weekly for an hour in the natural language exchange. Spontaneous speeches are collected between WJH and caregivers in a variety of activities indoors and outdoors, including eating, dressing, playing with toys, painting, reading, etc. Corpus collection starts from 1;8 and up to $2 ; 7$ there are a total of 51 video materials. Diaries and audio recordings are also made randomly at the same time.

\section{Corpus Collation}

After formatting videos through the Format Factory, spontaneous speeches are processed with ELAN according to CHILDES standards. Each discourse layer is named with abbreviations. CHI is for child's discourse layer, MOT for mother's discourse layer, FAT for father's discourse layer, GRM for grandmother's discourse layer and so on. For the activities such as singing, reciting, laughing and coughing, there are the explanation and description in English in the 
explanation layer. CLAN is mainly used to analyze Chinese modals in the 450,000-word corpus.

\section{ACQUISITION AND ANALYSIS}

Modal words can be classified into modal verbs and modal adverbs by the tests of VP-preposing and VP-ellipsis. If the VP right after a modal can be preposed or deleted, it goes to the category of modal verbs [8]. Thus the 15 modals in the corpus are roughly divided into the following two categories:

Modal verbs: hui, dei, neng, yao, xiang, keyi, gan, ken, yong, buzhun

Modal adverbs: yinggai, kending, keneng, bixu, yiding

TABLE I. STATISTICS AND COMPARISON OF THE 15 MODALS

\begin{tabular}{|c|c|c|c|c|}
\hline Modals & Emergence & $\begin{array}{c}\text { Acquisition } \\
\text { sequence }\end{array}$ & $\begin{array}{c}\text { Output } \\
\text { freq. }\end{array}$ & Input freq. \\
\hline hui 'will' & $1 ; 8 ; 20$ & 1 & 142 & 156 \\
\hline yao 'gonna' & $1 ; 8 ; 20$ & 1 & 1249 & 921 \\
\hline keyi 'can' & $1 ; 8 ; 27$ & 2 & 674 & 814 \\
\hline dei 'have to' & $1 ; 8 ; 27$ & 2 & 98 & 120 \\
\hline neng 'can' & $1 ; 9 ; 11$ & 3 & 379 & 659 \\
\hline $\begin{array}{c}\text { buzhun } \\
\text { 'can't' }\end{array}$ & $1 ; 9 ; 11$ & 3 & 10 & 8 \\
\hline xiang 'want' & $1 ; 10 ; 09$ & 4 & 207 & 468 \\
\hline yong 'need' & $1 ; 10 ; 23$ & 5 & 482 & 703 \\
\hline gan 'dare' & $2 ; 2 ; 02$ & 6 & 18 & 27 \\
\hline $\begin{array}{c}\text { kending } \\
\text { 'sure' }\end{array}$ & $2 ; 2 ; 10$ & 7 & 6 & 39 \\
\hline $\begin{array}{c}\text { yinggai } \\
\text { 'should' }\end{array}$ & $2 ; 2 ; 19$ & 8 & 21 & 62 \\
\hline $\begin{array}{c}\text { keneng } \\
\text { 'may' }\end{array}$ & $2 ; 3 ; 02$ & 9 & 24 & 53 \\
\hline $\begin{array}{c}\text { bixu 'must' } \\
\text { yiding 'must' }\end{array}$ & $2 ; 3 ; 07$ & 10 & 14 & 13 \\
\hline \hline
\end{tabular}

Modal verbs emerge at the beginning of the study, gradually between $1 ; 8-2 ; 2$ while adverbs emerge at $2 ; 2$. Besides, modals that are acquired early tend to occur more frequently. What's more, the input and output of modals are proportional by the comparison between their frequencies.

\section{A. Semantic Acquisition}

In this part, much attention is paid to the typical modal verbs yao, hui and neng which are acquired early and occur frequently in the corpus. Modal adverbs acquired are also analyzed to show the overall development of Chinese modals.

\section{1) Semantic acquisition of yao, hui and neng}

According to the degree of grammaticalization, yao, hui and neng can be used as dynamic modals, deontic modals, and epistemic modals in different contexts. Dynamic modals embody the ability or will of the subject of the sentence (see e.g. 1, 4, 7); deontic modals express the obligation, necessity, permission or properties of the subject (see e.g. 2, 5, 8); epistemic modals show the attitude of the speaker to the possibility or necessity of a proposition (see e.g. 3, 6, 9).

(1) (Uncle asks WJH whether he wants to try the food in the toy pot. $1 ; 8 ; 20$ (the age of 1 year 8 months and 20 days))

Bu yao changchang.

not want try

'I don't wanna try.'

(2) $(1 ; 9 ; 13)$

Wo yao niaoniao.

I want pee

'I wanna pee.'

(3) (WJH points at an object in the book. $1 ; 9 ; 11)$

Yao po.

gonna break

'It is gonna break.'

(4) (WJH imitates the flying action. $1 ; 8 ; 20$ )

Wo hui piao piao piao.

I can fly fly fly

'I can fly.'

(5) $(1 ; 9 ; 11)$

Guan men! Men hui jin feng.

close door door will enter wind

'Close the door! The wind will enter the door.'

(6) $(1 ; 11 ; 8)$

Chaoshi. Pingguo hui jin chaoshi.

supermarket apple will enter supermarket

'Supermarket. Apples will enter the supermarket.'

(7) (Mother asks WJH whether he is able to cut the tangerine skin with a fork. $1 ; 9 ; 25$ )

Ye bu neng qiedong.

also not can cut

'I can't cut it, neither.'

25)

(8) (Mother asks WJH whether she can eat candies. 1; 9;

\section{Bu neng chi.}

not can eat

'You can't eat.' 30)

(9) (Mother asks WJH to scrub a yellow square toy. 1; 10;

Zhege bu neng huai.

this not can bad

'It's impossible to go bad.'

TABLE II. COMPARISON BETWEEN THREE SEMANTIC TYPES OF YAO, HUI AND NENG

\begin{tabular}{|c|c|c|c|c|c|c|}
\hline \multirow{2}{*}{ Modals } & \multicolumn{2}{|c|}{ Dynamic modals } & \multicolumn{2}{c|}{ Deontic modals } & \multicolumn{2}{c|}{ Epistemic modals } \\
\cline { 2 - 7 } & $\begin{array}{c}\text { Emer- } \\
\text { gence }\end{array}$ & $\begin{array}{c}\text { Output } \\
\text { freq. }\end{array}$ & $\begin{array}{c}\text { Emer- } \\
\text { gence }\end{array}$ & $\begin{array}{c}\text { Output } \\
\text { freq. }\end{array}$ & $\begin{array}{c}\text { Emer- } \\
\text { gence }\end{array}$ & $\begin{array}{c}\text { Outpu } \\
\text { t freq. }\end{array}$ \\
\hline yao & $1 ; 8 ; 20$ & 873 & $1 ; 9 ; 13$ & 280 & $1 ; 9 ; 11$ & 96 \\
\hline hui & $1 ; 8 ; 20$ & 93 & $1 ; 9 ; 11$ & 39 & $1 ; 11 ; 8$ & 10 \\
\hline neng & $1 ; 9 ; 25$ & 226 & $1 ; 9 ; 25$ & 131 & $1 ; 10 ; 30$ & 22 \\
\hline
\end{tabular}

It's shown that the child has acquired the dynamic, deontic and epistemic usage of the three modals before $1 ; 12$. Epistemic modals not only emerge later than dynamic and deontic modals, but also occur less frequently. 


\section{2) Semantic acquisition of modal adverbs}

Modal adverbs yinggai, kending, keneng, bixu and yiding emerged between 2;2 and 2;5 and seldom occurred. The child has acquired the meanings of necessity, possibility, certainty and emphasis.

(10) $(2 ; 2 ; 19)$

Nage yinggai shi da huilang.

that should be big wolf

'That should be a big wolf.'

(11) $(2 ; 3 ; 23)$

Xiangxiang yinggai kai deng.

Xiangxiang should turn on light

'Xiangxiang should turn on the light.'

(12) $(2 ; 2 ; 19)$

Kending gou bu dao.

definitely reach not can

'Definitely I can't reach.'

(13) $(2 ; 3 ; 02)$

Keneng shi 7 ge shushu ba.

may be 7 uncle

'Maybe 7 uncles.'

(14) $(2 ; 6 ; 05)$

Zuo shuijiao bixu naxialai maozi.

make dumpling must take off hat

'You must take off the hat when making dumplings.'

(15) $(2 ; 7 ; 03)$

Yiding hen haochi.

must very delicious

'It must be very delicious.'

From the above corpus and analysis, it can be concluded that modals evolve from the lexical category to the functional category and from the individual attribute (willingness or ability) to the uncertainty of a proposition through the intermediary stage (obligation, necessity, permission or properties).

\section{B. Syntactic Acquisition}

Generally there are three characteristics of the syntactic acquisition shown in the corpus.

First, modal sentences show a trend of gradual diversification. The child's earliest output was the simple affirmative or negative reply to parents' questions and then he began to produce a complete spontaneous statement (see e.g. 1). Questions occurred at 2; 2 (see e.g. 16). But they only account for $2 \%$ in the corpus.

(16) $(2 ; 2 ; 23)$

Neng wan dianyaliguo ba?

can play electric pressure cooker

'Can I play the electric pressure cooker?'

Second, the syntactic structure of modal sentences presents a trend of gradual complication. The child's earliest output was the relatively simple statement without a subject. Soon he learned to use the negative adverb $b u$ 'not' and at $1 ; 11$ repeated adverb hai 'also' emerged. Gradually modal verbs were modified by the adverbs of time (xianzai 'now', xian (first), yihui 'in a while', deng Xiangxiang zhangda 'when Xiangxiang grows up') and adverbs of place (zheer 'here') and adverbs of emphasis (iiu, cai, zhende 'really') and adverbs of manner (zheme 'like this') . The ba - sentences came up at 1; 11. From 2; 2, the aspect of zhe emerged in the modal sentence showing the continuation of the action. And le was employed to indicate a change at 2; 4.

(17) (Mother asks WJH what characters he would like to write. $1 ; 11 ; 13)$

Xie "guo". Hai yao xie ge "chao".

write "Guo" also want write a "chao"

'Write the character "Guo" and also "Chao".'

(18) $(1 ; 11 ; 30)$

Wo yao ba shui daodiao.

I will let water empty out

'I'll empty the water out.'

(19) $(2 ; 2 ; 02)$

Wo yao feizhe.

I will flying

'I'll be flying.'

(20) $(2 ; 4 ; 01)$

Tanke yao jiaocai le.

tank will water plants

'The tank is going to water plants.'

Third, there is a co-occurrence relationship between the semantic type of modals and the subject orientation. Dynamic modality and first-person subjects often co-occur and these sentences express the ability of subjects or their desire to achieve (see e.g. 1, 4, 7). The subjects in deontic modal sentences are often oriented towards other people, restricting or permitting their words and deeds (see e.g. 8). Epistemic modality generally speculates on the possibility with subjects of sentences referring to someone else or something else (see e.g. $3,6,9)$.

\section{Correspondence between Semantic Interpretation and} Syntactic Distribution

\section{1) Co-occurrence restriction}

(21) (Child is to get the shovel. 2; 3; 07)

Zhe bixu dei yao chan wanju.

this must must need shovel toy

'It must use the toy shovel.'

Example 21 shows the coexistence of modal verbs and modal adverbs. When bixu in the sentence shows the necessity, the modal dei following it has the meaning of obligation or possibility; when bixu expresses the obligatory meaning, the latter embodies nothing but the obligation.

(22) (CHI is fanning a ball. $2 ; 4 ; 01)$

Dei yao na shanzi.

should need get fan

'Should get the fan.'

(23) $(2 ; 7 ; 03)$

Wo xiang yao niaoniao.

I want want pee

'I want to pee.'

The coexistence of modal verbs is shown in Examples 22 and 23. Yao expresses the meaning of obligation or demand when it occurs after a deontic modal (see e.g. 22); yao embodies the willingness when it is with a dynamic modal 
(see e.g. 23).

\section{2) Modals and negatives}

$B u$ 'not' and mei(you) 'haven't/didn't' are the two commonly-used negatives in modal sentences. $\mathrm{Bu}$ is an irrealis negative while mei(you) serves as a realis negative. The child began to produce negative statements using $b u$ at $1 ; 8$ and almost all of bus were semantically and syntactically correct in the corpus. Mei(you) also occurred in a few sentences to express negative meanings, but none of them were used properly (see e.g. 24, 25). It's seen that the child failed to realize that deontic modals cannot be used in conjunction with realis negatives during the early acquisition process.

(24) (Mother asks WJH whether she can eat hot. 1; 10;18) Meiyou.

haven't/didn't

'No, you didn't/haven't.'

(25) (Mother says scratching will help. 1; 11;07)

Meiyou hui.

haven't/didn't will

'No, it didn't/hasn't.'

\section{3) Modals and interrogatives}

Interrogative words occur in both statements and questions in the corpus. Epistemic modals license the indefinite use of interrogative words while dynamic and deontic modals license their interrogative use.

(26) $(1 ; 6 ; 18)$

Shenme dou bu yao zuo.

what all not want do

'I wanna do nothing.'

(27) $(1 ; 8 ; 06)$

Yingqai qu na?

should go where

'Where should go?'

(28) $(1 ; 8 ; 06)$

Ni xiang yong nage shouji?

you want use which mobile

'Which mobile do you want to use?'

In the corpus, the correspondence between semantic interpretation and syntactic distribution of modals has been reflected in the coexistence of modals and the interaction with negatives as well as interrogatives, which means the proper use of modals in different contexts, has been acquired to a certain extent in the pragmatic respect.

\section{CONCLUSION}

The study tracks the early modal acquisition of a Chinese child from $1 ; 8$ to $2 ; 7$ and finds that: modal verbs have emerged at $1 ; 8$ and epistemic modals among the three types occur late and less frequently; modal adverbs are acquired later between $2 ; 2-2 ; 5$ and feature low frequency; the expression of modal sentences is gradually diversified and the syntactic structure is gradually complicated; the use of modals embodies the correspondence between semantics and syntax.

In view of the limitations of the study, the in-depth followup study can further investigate other modal forms (intonation, inflection, auxiliary verbs, particles, adjectives and nouns) and explore the underlying factors constraining early modal acquisition and the cognitive development of the child.

\section{REFERENCES}

[1] Fan Li, "The child early acquisition of postverbal modality in Mandarin," Language Theory Research, vol. 6, 2010. (In Chinese)

[2] Gopnik. A. and J. Astington, "Children's understanding of representational change in its relation to the understanding of false belief and the appearance-reality distinction," Child Development, (59), 1988.

[3] Kong Lingda, A Study on Chinese Children's Notional Word Acquisition. Hefei: Anhui University Press, 2004. (In Chinese)

[4] Ozge Ozturk and Anna Papafragou, "The acquisition of epistemic modality: from semantic meaning to pragmatic interpretation," Language Learning and Development, (3), 2015.

[5] Peng Lizhen, Modality of Modern Chinese. Beijing: China Social Science Press, 2007. (In Chinese)

[6] Portner Paul, Modality. Oxford: Oxford University Press, 2009.

[7] Shatz. M and S. Wilcox, "Constraints on the acquisition of English modality," In S. Gelman and J. Byrnes (eds.), Perspectives on Language and Thought. Cambridge: Cambridge University Press, 1991.

[8] T.-H. Jonah Lin, "Multiple-modal constructions in Mandarin Chinese and their finiteness properties," Journal of Linguistics, vol. 48, Issue 01, 2012.

[9] Yang Bei and Dong Yanping, "Early acquisition of Chinese modal verbs: a case study," Journal of Foreign Languages, Vol. 37 No. 1, 2014. (In Chinese)

[10] Zhang Yunqiu and Wang Yuting, "A case study of the acquisition of the subjectivisation markers in Beijing Mandarin," Studies of the Chinese Language, vol. 5, 2011. (In Chinese) 